Received: 2020-01-22

\title{
Research on polyphenols extraction from Polygonum multiflorum Thunb. roots
}

\author{
LE PHAM TAN QUOC
}

Institute of Biotechnology and Food Technology

Industrial University of Ho Chi Minh City

Ho Chi Minh City

Vietnam

phone 084906413 493, e-mail: lephamtanquoc@iuh.edu.vn

\section{Summary}

Introduction: Polygonum multiflorum Thunb. is a herbal common plant in Asia, with many beneficial health effects for human because it contains many bioactive compounds which can prevent some diseases, for instance such as cardiovascular diseases, cancers, neurodegenerative diseases, etc.

Objective: The purpose of this research is to point out the effects of extraction factors such as type of solvent, material/solvent ratio $(w / v)$, solvent concentration $(\%, v / v)$, temperature $\left({ }^{\circ} \mathrm{C}\right)$ and extraction time on the extraction yield of phenolic compounds from Polygonum multiflorum Thunb. roots, for instance, total polyphenol content (TPC) and antioxidant capacity (AC).

Methods: The raw material consisting of Polygonum multiflorum Thunb root was extracted by the reflux maceration method. TPC and AC of received extract were evaluated by the Folin-Ciocalteu technique and DPPH method with Trolox as a standard agent.

Results: The optimal conditions for the extraction process were acetone-water mixture $(60 \%, v / v)$ as a solvent, material/solvent ratio of $1 / 40$, extraction temperature of $50^{\circ} \mathrm{C}$ and extraction time of 90 minutes. The surface structure of material after extraction process changed insignificantly compared with the initial structure.

Conclusion: The results showed that TPC and AC obtained the best values $(38.60 \pm 0.56 \mathrm{mg}$ GAE/g DW (dry weight) and $298.15 \pm 2.99 \mu \mathrm{mol} \mathrm{TE} / \mathrm{g} \mathrm{DW}$, respectively) at optimal extraction conditions. In addition, some phenolic compounds were detected in the extract such as gallic acid, catechin and resveratrol.

Key words: antioxidant, extract, phenolic compounds, Polygonum multiflorum Thunb.

Słowa kluczowe: właściwości antyoksydacyjne, związki fenolowe, Polygonum multiflorum Thunb. 


\section{INTRODUCTION}

Polyphenols are precious substances present in various plants. Among them, Polygonum multiflorum Thunb. roots also contained a large number of phenolic compounds such as flavonols [1], emodin, physcion [2], torachrysone-8- O- $\beta$-D-glucoside and rhaponticoside [3], etc. This is a wild medical herb also cultivated widely in some Asian countries, especially in North Vietnam. The root has been used for the treatment of many diseases such as cardiovascular diseases, diabetes, osteoporosis, etc. [4] during a thousand years because of the presence of these bioactive compounds, especially polyphenols. In addition, $P$. multiflorum roots has been used as a seasoning in daily Chinese diet [5]. Yet, polyphenols extract from this plant has not been applied in the food industry. This will create a new foundation for further research on P. multiflorum roots such as the extraction process.

Currently, the extraction of phenolic compounds from herbal plants has been usually performed with use of various methods, such as maceration, Soxhlet, ultrasonic-assisted extraction (UAE), microwave-assisted extraction (MAE), etc. with many different solvents [6] or enzyme-assisted extraction (EAE) [7]. However, each one has its advantages and disadvantages. The reflux maceration extraction can have a long extraction time but it is a process quite easy to control, of low budget and suitable in lab scale. In Vietnam, herbal plants are almost harvested, processed and the bioactive compounds are extracted by local inhabitants of mountainous region. Although, there are many modern extraction methods (UAE, MAE or EAE) improve the amount of extracted polyphenols from plants, especially from P. multiflorum roots [8-10]. However, it is very difficult to scale up for these methods in the current condition in Vietnam. Therefore, maybe the traditional extraction methods are still a primary choice, especially the reflux maceration method.

Besides, no studies were performed using reflux maceration method for the polyphenols extraction from P. multiflorum roots. Therefore, the aim of this research was to determine the optimum extraction conditions, for instance, the type and concentration of solvent, material/solvent ratio, extraction time and extraction temperature for the extraction of TPC and AC from this material. In addition, some main phenolic compounds of this extract were determined by high performance liquid chromatography (HPLC) method. Besides, the structure of materials was also observed by scanning electron microscope (SEM).

\section{MATERIAL AND METHODS}

\section{Sample preparation}

P. multiflorum roots were obtained from Cao Bang province (Vietnam). The weight of fresh roots was approximately $1 \mathrm{~kg}$. The colour of the skin is reddishbrown and these roots had no damages or physical injuries. Then, they were rinsed with tap water and cut into small pieces (thickness of 2-3 mm) and dried in an oven at $60^{\circ} \mathrm{C}$ (until the moisture is lower than $12 \%)$. Dried slices were ground into fine powder by a disintegrator and sieved through a $0.5 \mathrm{~mm}$ screen. Finally, the obtained powdered samples were packaged in vacuum conditions and stored at a room temperature for further use.

\section{Chemicals and reagents}

Chemical agents in this study were obtained from Sigma-Aldrich (USA) and Merck (Germany) such as Trolox (6-hydroxy-2,5,7,8-tetramethylchroman2-carboxylic acid) reagent, DPPH (2,2-diphenyl1-picrylhydrazyl) and Folin-Ciocalteu reagent. Other chemicals used were of analytical reagent grade.

\section{Extraction process}

Dried powder was extracted with some solvents (distilled water, aqueous ethanol, aqueous methanol and aqueous acetone, solvents concentrations ranged $40-80 \%, v / v)$ in a heater for different times (30-120 minutes) at required temperature (30$\left.70^{\circ} \mathrm{C}\right)$ and material/solvent ratio $(1 / 10-1 / 50, v / w)$. The mixture was mixed by a magnetic stirrer and the solvent was refluxed by the condenser system. After that, it was filtered for removal of roots particles with support of the vacuum filtration system and finally, TPC and AC were determined.

\section{Determination of TPC in extracts}

The TPC was estimated by the Folin-Ciocalteu method with slight modifications [11]. TPC was expressed as mg of gallic acid equivalents per gram of dry weight (mg GAE/g DW), based on a calibration curve of gallic acid. 


\section{Determination of $\mathrm{AC}$ in extracts}

Based on the method of Soto et al. [12] with slight modifications, the AC was assessed by DPPH assay. To obtain the calibration curve, the absorbance at $517 \mathrm{~nm}$ of a series of concentrations of Trolox was recorded and AC was expressed in TEAC (Trolox Equivalent Antioxidant Capacity). Trolox was used as a standard and expressed as $\mu \mathrm{mol}$ of Trolox per gram of dry weight ( $\mu \mathrm{mol} \mathrm{TE} / \mathrm{g} \mathrm{DW})$.

\section{HPLC analysis}

The phenolic profiles in optimal extracts were analysed by an Agilent 1100 Series HPLC system equipped with a diode-array UV-VIS detector. A reversed-phase column (Kromasil C18, $150 \times 2.1 \mathrm{~mm}, 3.5 \mu \mathrm{m}$ ) was used and the UV detector was set at a wavelength of $270 \mathrm{~nm}$ for gallic acid and catechin; $308 \mathrm{~nm}$ for resveratrol. All samples were injected into the injection port (loop $20 \mu \mathrm{l}$ ) with a flow rate of $0.2 \mathrm{ml} / \mathrm{min}$ at $30^{\circ} \mathrm{C}$. The gradient programme with a two-solvent system (A: hydrochloric acid; B: methanol) was used to analyse and the standard phenolic compound solutions (gallic acid, catechin and resveratrol) were prepared in the solvent used for extractions.

\section{Scanning electron micrographs (SEM)}

A scanning electron microscope system (Jeol JSM-7401F, USA) was used to determine morphological alterations of dried powder samples before and after extraction under high vacuum condition at an accelerating voltage of $5 \mathrm{kV}(10 \mu \mathrm{m}$, $2000 \times$ magnification).

\section{Statistical analysis}

The results reported in this study are the average of at least three measurements and they were expressed as means \pm standard deviations (SD). The received data were calculated and statistically analysed using the Statgraphics software (Centurion XV). Differences between means were determined by analysis of variance (ANOVA) with Fisher's least significant difference (LSD) procedure on the confidence level superior declared at $p<0.05$.

Ethical approval: The conducted rsearch is not related to either human or animal use.

\section{RESULTS AND DISCUSSION}

\section{Effect of type of solvent on TPC and AC}

The dried powder samples were extracted with various solvents such as $50 \%$ methanol, $50 \%$ ethanol, $50 \%$ acetone and distilled water under the same extraction conditions, including material/solvent ratio of $1 / 20$, and temperature of $50^{\circ} \mathrm{C}$ in 60 minutes. The results showed that TPC and AC of extracts differ from other solvents $(p<0.05)$. This pointed out that the solvent strongly affects the polyphenols extraction. The maximum TPC was $30.43 \pm 0.78 \mathrm{mg} \mathrm{GAE} / \mathrm{g}$ DW and AC was $221.56 \pm 3.83 \mu \mathrm{mol}$ $\mathrm{TE} / \mathrm{g}$ DW at acetone concentration of $50 \%$ (fig. 1).

The solvent choice for the extraction process is quite important mainly because it can increase or decrease TPC and AC levels in the extract. Many studies proved that TPC and AC depend on the polarity of solvent and solubility of phenolic compounds in various solvents $[8,13]$. In fact, methanol, ethanol

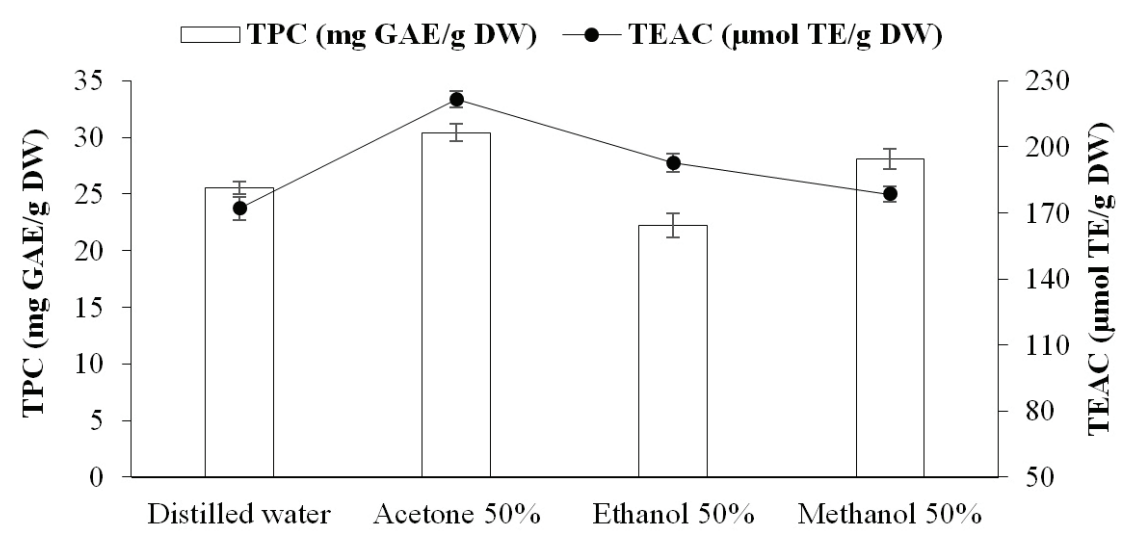

Solvents

Figure 1

$\mathrm{TPC}$ and $\mathrm{AC}$ of extracts at various solvents 
and acetone were used for extracting phenolic compounds from plants, especially the mixture of organic solvent and water [14]. The highest polar solvent (water) or the lowest polar solvent (hexane or chloroform) is also not suitable for extracting these bioactive compounds because water could dissolve some impurities, such as protein or sugar. They significantly affect the received result [15], especially TPC. At the same time, phenolic compounds are polar compounds. Thus, they cannot dissolve completely in the unsuitable polar solvent. Hence, the yield of the extraction process is low. Many studies also proved that aqueous acetone is an optimum solvent to extract phenolic compounds from plants such as elderberry, grape marc [16] and neem leaves [17]. Accordingly, aqueous acetone was a suitable solvent for the next steps.

\section{Effect of material/acetone ratio on the TPC and AC}

Figure 2 shows that there are significant differences of TPC and AC levels between various material/acetone ratios $(p<0.05)$. However, the material/acetone ratio of $1 / 40$ led to the best values. Both TPC and $\mathrm{AC}$ obtained maximum values $(33.72 \pm 0.44 \mathrm{mg}$ GAE/g DW and 235.52 $\pm 3.5 \mu \mathrm{mol} \mathrm{TE} / \mathrm{g} \mathrm{DW}$ ). The material/acetone ratio is also the most important factor of the extraction process: it can strongly affect the extraction yield as TPC and AC.

An increase of the amount of solvent can lead to a quick increase of the yield of extraction and then the yield peaked at material/acetone ratio of $1 / 40$, before slow decrease. Increasing the level of solvent can promote the diffusion of polyphenols into solvent and dissolution of polyphenols can improve rapidly [18]. This process lasts continuously until the equilibrium is reached [19]. If the amount of solvent is too large, the yield gained is insignificant and would not be cost-effective because of time and energy consumed to chase a volume solvent. On the other hand, a small amount of solvent cannot completely extract polyphenols from materials [8].

The material/solvent ratio depends on materials, solvents, extraction methods, etc. The received material/solvent ratio in this case is higher than that of Tabaraki et al. [20], they extracted polyphenols from Punica granatum $\mathrm{L}$. fruit with that of $1 / 50$ by ultrasonic-assisted extraction, or lower than that of Tan et al. [21], who extracted polyphenols from Centella asiatica with that of $1 / 15$ by maceration method. From the results obtained, the material/solvent ratio of $1 / 40$ was used for further experiments.

\section{Effect of solvent concentrations on TPC and AC}

The results showed that $\mathrm{TPC}$ and $\mathrm{AC}$ were significantly different at different acetone concentrations $(p<0.05)$. The highest TPC and AC were $36.5 \pm 3.14 \mathrm{mg} \mathrm{GAE} / \mathrm{g}$ DW and $281.39 \pm 3.21 \mu \mathrm{mol}$ $\mathrm{TE} / \mathrm{g} \mathrm{DW}$ at acetone concentration of $60 \%$, respectively (fig. 3). That means that the polarity of polyphenols in the extract was medium. The extraction yield increased dramatically at acetone concentration from $40 \%$ to $60 \%$, then decreased rapidly with an increase of acetone concentration of $80 \%$. The combination of acetone and water is the

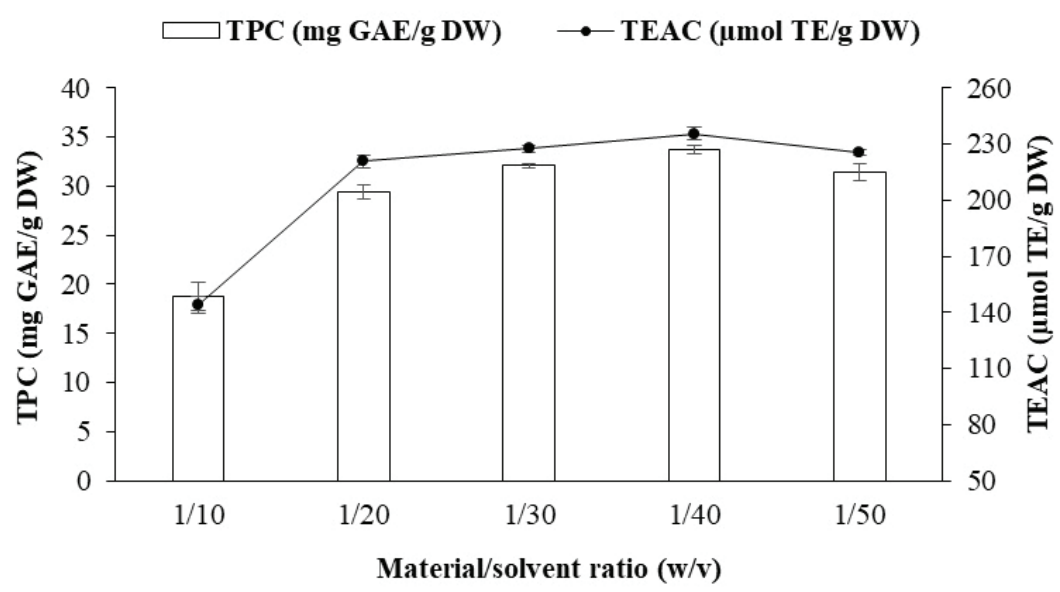

Figure 2

$\mathrm{TPC}$ and $\mathrm{AC}$ of extracts at various material/solvent ratios 


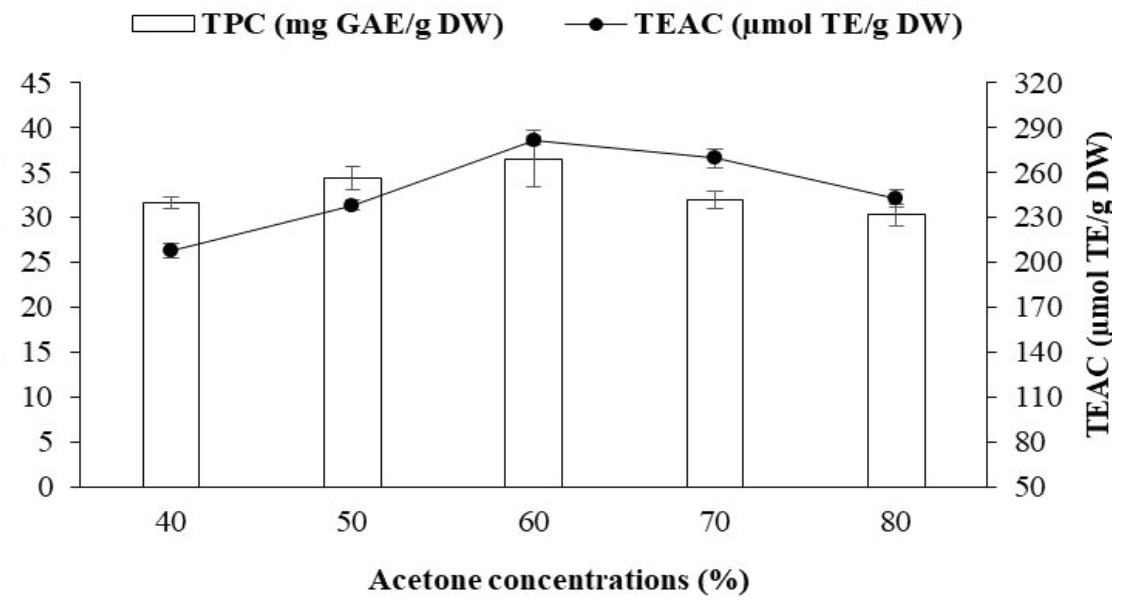

Figure 3

TPC and AC of extracts at various acetone concentrations

optimum solvent to extract phenolic compounds in this study. Water can diffuse easily into the plant cell, lead to facilitating the movement of bioactive compounds into the extracting solvent [22].

The optimum acetone concentration in this experiment is higher than that of other researches, for instance, Hismath et al. [17] extracted polyphenols from neem leaves with acetone concentration of $48.49 \%$ by water bath shaker extraction and Addai et al. [23] used acetone concentration of $50 \%$ to extract polyphenols from papaya by maceration method. However, this result is also similar to that of Quoc and Muoi [8], who extracted these compounds from $P$. multiflorum roots with acetone concentration of $60 \%$ by ultrasonic-assisted extraction. This means that TPC and AC depend on solvent concentration, extraction method and initial material. Accordingly, the suitable acetone concentration for the next experiment was $60 \%$.

\section{Effect of extraction time and extraction tempe- rature on TPC and $\mathrm{AC}$}

Extraction time and extraction temperature are the most important factors, which affect directly the TPC and AC. TPC and AC in the extract were significantly different for all extraction time and temperature $(p<0.05)$. The yield obtains the maximum value at $50^{\circ} \mathrm{C}$ for 90 minutes, the TPC and AC values dramatically increased to $38.60 \pm 0.56 \mathrm{mg} \mathrm{GAE} / \mathrm{g}$ DW (fig. 4) and 298.15 $\pm 2.99 \mu \mathrm{mol} \mathrm{TE} / \mathrm{g}$ DW (fig. 5), respectively. In general, the yield of the extraction process increases quickly with increasing extraction time from 30 to $90 \mathrm{~min}$ and extraction temperature from 30 to $50^{\circ} \mathrm{C}$. Then, it sharply drops for the rest of time and temperature.

The bioactive compounds are easily degraded at high temperatures and long extraction time,

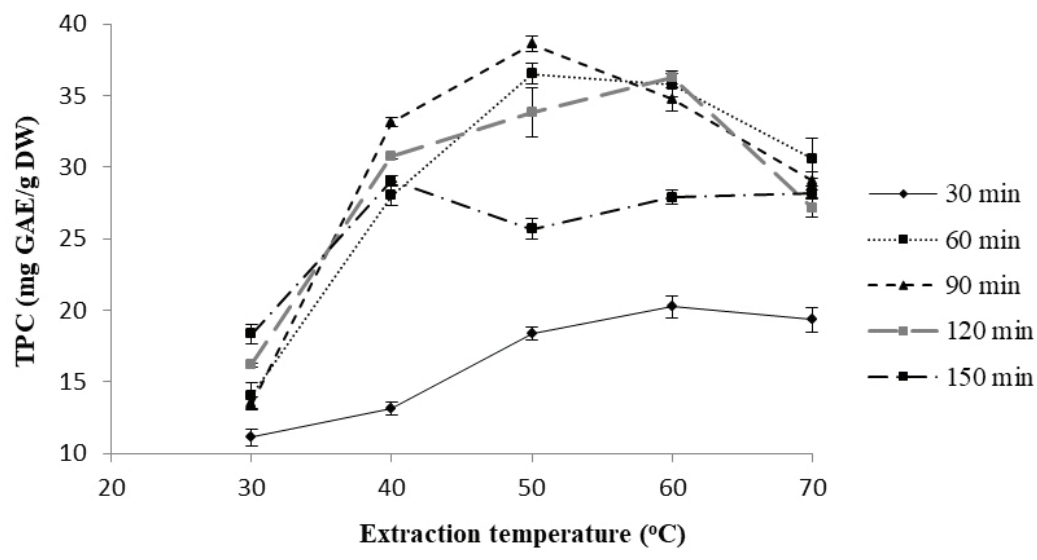

Figure 4

TPC of extracts at various extraction temperatures and extraction times 


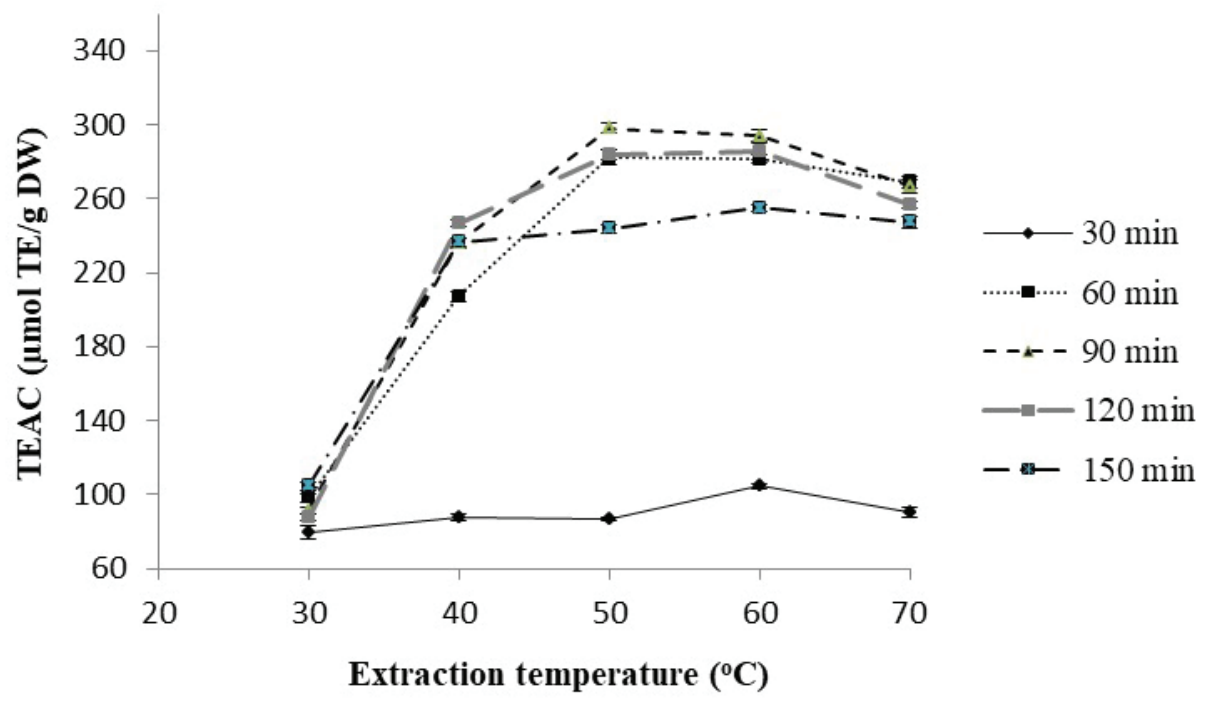

Figure 5

$\mathrm{AC}$ of extracts at various extraction temperatures and extraction times

especially phenolic compounds. They can be also degraded by oxygen, light and high temperature in the surrounding environment. However, high temperatures can improve the extraction yield because of promoting the diffusion of polyphenols and reducing the solvent viscosity [24]. In this case, the extraction temperature is the best choice. It is lower than that of Quoc and Muoi [8] who extracted polyphenol from $P$. multiflorum roots by ultrasonic-assisted extraction at $60^{\circ} \mathrm{C}$.

Extending the extraction time can improve TPC and AC mainly because they were extracted completely. However, in some cases, the yield increases insignificantly with longer extraction time [25]. Suitable extraction time saves time and costs of the implementation process [26]. The extraction time in this study was longer than that of the study of Quoc and Muoi [9], who also extracted polyphenols from P. multiflorum roots by microwave-assisted extraction for 5 minutes or shorter than that of the study of Zheng et al. [7] who used viscozyme L to extract polyphenols from unripe apples for 12 hours. For these reasons, extraction time and extraction temperature depend on the extraction method and material used. Based on the achieved results, the optimal treatment conditions in this study are the extraction temperature of $50^{\circ} \mathrm{C}$ and the extraction time of $90 \mathrm{~min}$ utes.

\section{Determination of the structure of material be- fore/after the extraction process and individual polyphenols content}

Figure 6 points out that initial samples include some parts of cell plants and starch which have the various diameter and egg/oval/sphere shape. After the extraction process, starch is not gelatinized at $50^{\circ} \mathrm{C}$ and a few wrinkles and fragments appear on the surface of the cell wall. This proved that this extraction process affects insignificantly the initial material.

Figure 7 and 8 show that some specific phenolic compounds were also detected in the extract such as catechin $(1.98 \mathrm{mg} / \mathrm{g})$, gallic acid $0.58(\mathrm{mg} / \mathrm{g})$ and resveratrol $(0.023 \mathrm{mg} / \mathrm{g})$. These results are not similar to those of Quoc and Muoi $[8,9]$ in the same material; although, the materials were harvest in the same place. This means that the extraction methods affect the content of the specific phenolic compounds strongly.

\section{CONCLUSIONS}

The results recorded show that acetone is the best solvent that can increase the yield of polyphenols extraction from $P$. multiflorum roots. The best TPC and $\mathrm{AC}$ values were $38.60 \pm 0.56 \mathrm{mg} \mathrm{GAE} / \mathrm{g}$ DW and $298.15 \pm 2.99 \mu \mathrm{mol} \mathrm{TE} / \mathrm{g}$ DW at the optimal extraction conditions (60\% aqueous acetone, material/solvent 

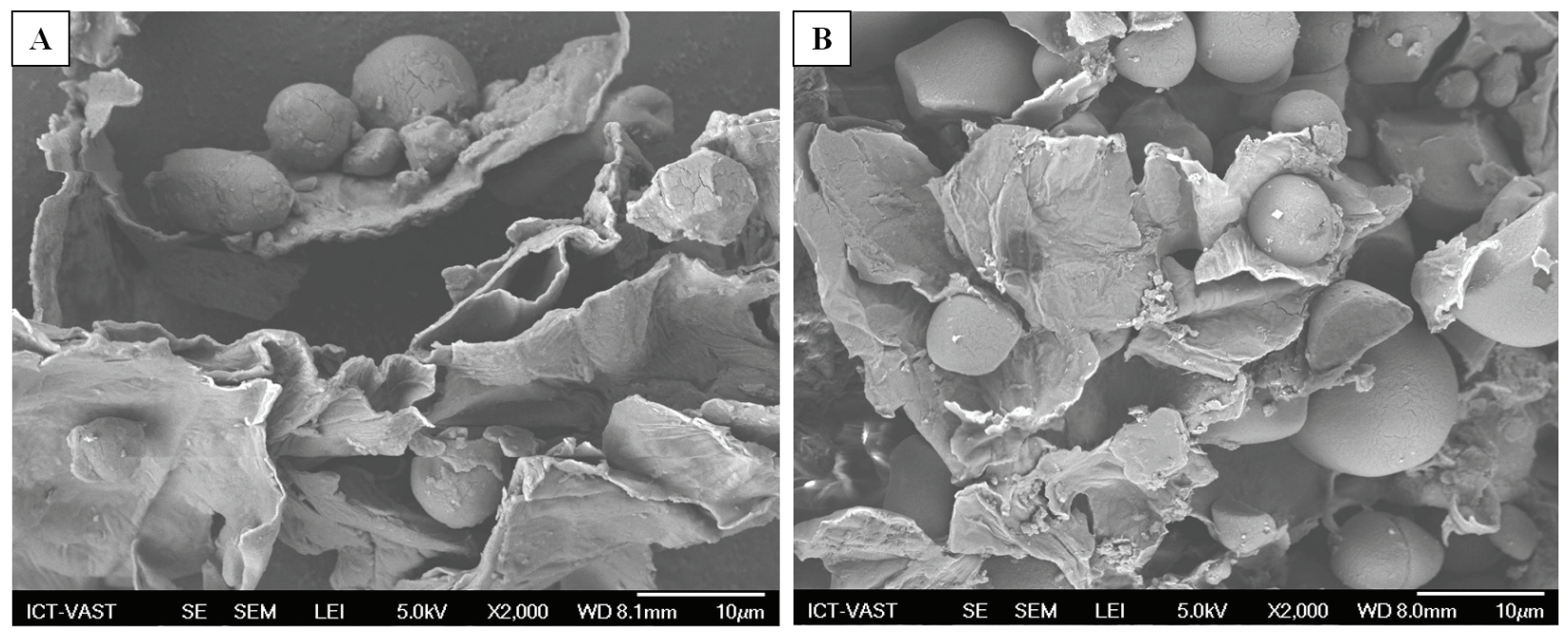

Figure 6

Structure of material before (A) and after (B) extraction process
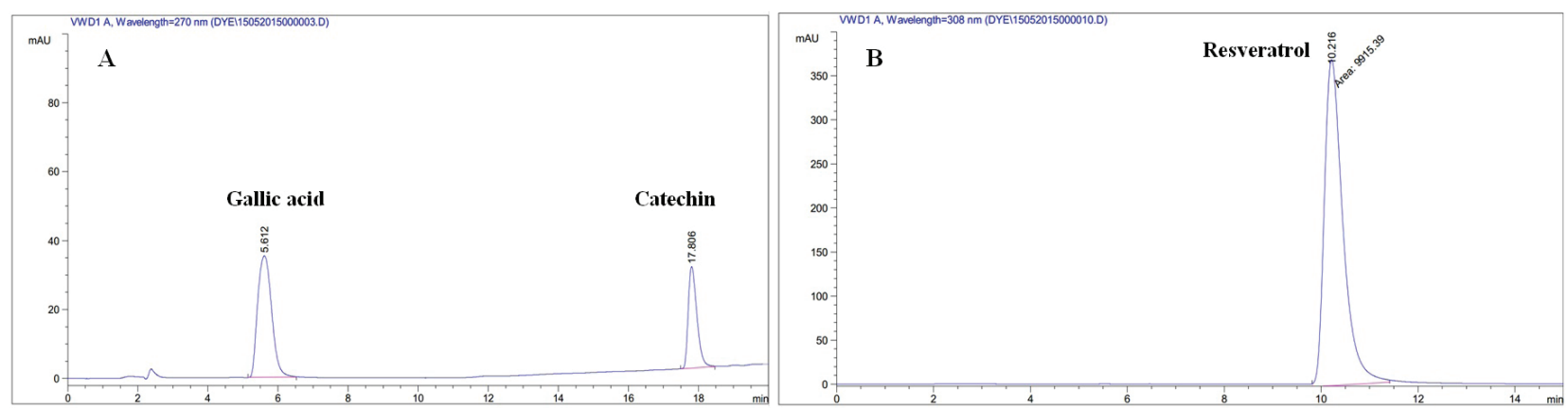

Figure 7

HPLC chromatograms of a mixed standard solutions of gallic acid, catechin and resveratrol
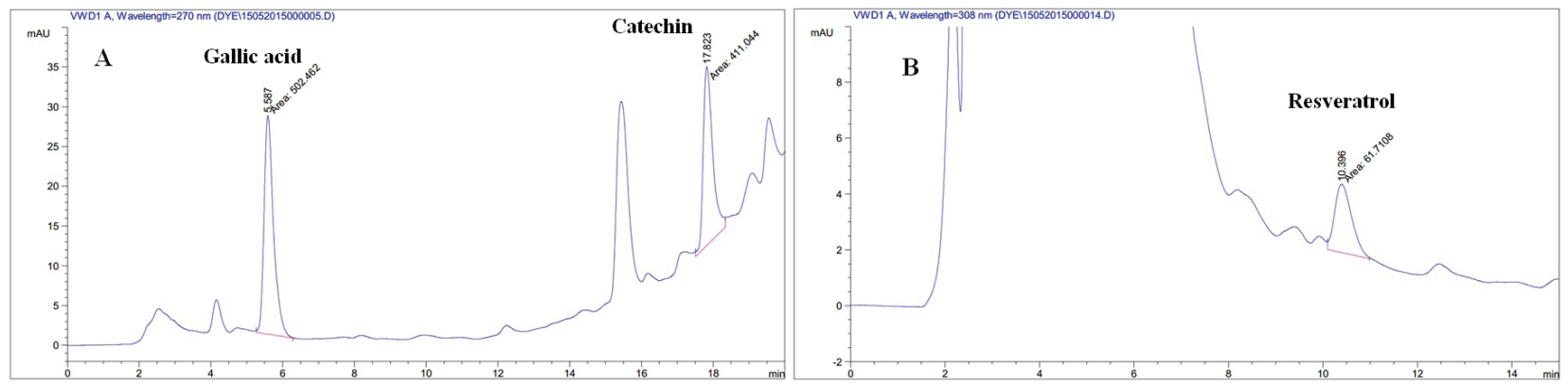

Figure 8

HPLC chromatograms of a sample of Polygonum multiflorum Thunb. root extracts acquired at $270 \mathrm{~nm}$ (A) and $308 \mathrm{~nm}$ (B)

ratio of $1 / 40$, extraction time of 90 minutes and extraction temperature of $50^{\circ} \mathrm{C}$ ). Cell wall was not affected significantly by acetone and the received extract has the presence of the main phenolic compounds as catechin, gallic acid and resveratrol.

Conflict of interest: Authors declare no conflict of interest.

\section{REFERENCES}

1. Xu ML, Zheng MS, Lee YK, Moon DC, Lee CS, Woo $\mathrm{MH}$, et al. A new stilbene glucoside from the roots of Polygonum multiflorum Thunb. Arch Pharm Res 2006; 29:946-951.

2. Liang Z, Chen H, Yu Z, Zhao Z. Comparison of raw and processed Radix Polygoni Multiflori 
(Heshouwu) by high performance liquid chromatography and mass spectrometry. Chin Med 2010; 5:1-9. doi: http://dx.doi.org/10.1186/17498546-5-29

3. Yi T, Leung KSY, Lu GH, Zhang H, Chan K. Identification and determination of the major constituents in traditional chinese medicinal plant $\mathrm{Po}$ lygonum multiflorum Thunb. by HPLC coupled with PAD and ESI/MS. Phytochem Anal 2007; 18(3):181-187. doi: http://dx.doi.org/10.1002/ pca.963

4. Scalbert A, Manach C, Morand C, Remesy C, Jimenez L. Dietary polyphenols and the prevention of diseases. Crit Rev Food Sci Nutr 2005; 45(4):287-306. doi: http://dx.doi. org/10.1080/1040869059096

5. Li R, Gao HM. Polygonum multiflorum Thunb. (Heshouwu, Tuber Fleeceflower Root). In: Liu Y, Wang Z, Zhang J (eds.). Dietary Chinese Herbs Chemistry, Pharmacology and Clinical Evidence. Wien, NewYork 2015:227-234.

6. Wang L, Weller CL. Recent advances in extraction of nutraceuticals from plants. Trends Food Sci Technol 2006; 17(6):300-312. doi: http:// dx.doi.org/10.1016/j.tifs.2005.12.004

7. Zheng HZ, Hwang IW, Chung SK. Enhancing polyphenol extraction from unripe apples by carbohydrate-hydrolyzing enzymes. J Zhejiang Univ Sci B 2009; 10(12):912-919. doi: http://dx.doi. org/10.1631/jzus.B0920186

8. Quoc LPT, Muoi NV. Ultrasound-assisted extraction of phenolic compounds from Polygonum multiflorum Thunb. roots. Bulg J Agric Sci 2018; 24(2):229-235.

9. Quoc LPT, Muoi NV. Microwave-assisted extraction of phenolic compounds from Polygonum multiflorum Thunb. roots. Acta Sci Pol Technol Aliment 2016; 15(2):181-189. doi: http://dx.doi. org/10.17306/J.AFS.2016.2.18

10. Quoc LPT, Muoi NV. Pectinase-assisted extraction of phenolic compounds from Polygonum multiflorum Thunb. root. Carpathian J Food Sci Technol 2017; 9(3):30-37.

11. Siddiqua A, Premakumari KB, Sultana R, Vithya, Savitha. Antioxidant activity and estimation of total phenolic content of Muntingia calabura by colorimetry. Int J ChemTech Res 2010; 2(1):205208.

12. Soto C, Caballero E, Pérez E, Zúñiga ME. Effect of extraction conditions on total phenolic content and antioxidant capacity of pretreated wild Peumus boldus leaves from Chile. Food Bioprod Process 2014; 92(3):328-333. doi: http://dx.doi. org/10.1016/j.fbp.2013.06.002

13. Zhang L, Tu ZC, Yuan T, Wang H, Fu Z, Wen Q, et al. Solvent optimization, antioxidant activity, and chemical characterization of extracts from Artemisia selengnesis Turcz. Ind Crops Prod 2014; 56:223-230. doi: http://dx.doi.org/10.1016/j.indcrop.2014.03.003

14. Meneses NGT, Martins S, Teixeira JA, Mussatto SI. Influence of extraction solvents on the recovery of antioxidant phenolic compounds from brewer's spent grains. Sep Purif Technol 2013; 108:152-158. doi: http://dx.doi.org/10.1016/j.seppur.2013.02.015

15. Chirinos R, Rogez H, Campos D, Pedreschi R, Larondelle Y. Optimization of extraction conditions of antioxidant phenolic compounds from mashua (Tropaeolum tuberosum Ruíz \& Pavón) tubers. Sep Purif Technol 2007; 55:217-225. doi: http://dx.doi.org/10.1016/j.seppur.2006.12.005

16. Vatai T, Škerget M, Knez Z. Extraction of phenolic compounds from elder berry and different grape marc varieties using organic solvents and/ or supercritical carbon dioxide. J Food Eng 2009; 90(2):246-254. doi: http://dx.doi.org/10.1016/j. jfoodeng.2008.06.028

17. Hismath I, Wan-Aida WM, Ho CW. Optimization of extraction conditions for phenolic compounds from neem (Azadirachta indica) leaves. Int Food Res J 2011; 18(3):931-939.

18. Zhang SQ, Bi HM, Liu CJ. Extraction of bioactive components from Rhodiola sachalinensis under ultrahigh hydrostatic pressure. Sep $\mathrm{Pu}-$ rif Technol 2007; 57:277-282. doi: http://dx.doi. org/10.1016/j.seppur.2007.04.022

19. Herodež SS, Hadolin M, Škerget M, Knez Ž. Solvent extraction study of antioxidants from Melissa officinalis L. leaves. Food Chem 2003; 80(2):275-282. doi: http://dx.doi.org/10.1016/ 


\section{S0308-8146(02)00382-5}

20. Tabaraki R, Heidarizadi E, Benvidi A. Optimization of ultrasonic-assisted extraction of pomegranate (Punica granatum L.) peel antioxidants by response surface methodology. Sep Purif Technol 2012; 98:16-23. doi: http://dx.doi.org/10.1016/j. seppur.2012.06.038

21. Tan PW, Tan CP, Ho CW. Antioxidant properties: Effects of solid-to-solvent ratio on antioxidant compounds and capacities of pegaga (Centella asiatica). Int Food Res J 2011; 18:557-562.

22. Veggi PC, Martinez J, Meireles MAA. Fundamentals of Microwave Extraction. In: Chemat F, Cravotto G (eds.). Microwave-assisted extraction for bioactive compounds - theory and practice. NewYork 2013: 15-52.

23. Addai ZR, Abdullah A, Mutalib SA. Effect of extraction solvents on the phenolic content and antioxidant properties of two papaya cultivars. J Med Plants Res 2013; 7(47):3356-3358. doi: http://dx.doi.org/10.5897/JMPR2013.5116
24. Wissam Z, Ghada B, Wassim A, Warid K. Effective extraction of polyphenols and proanthocyanidins from pomegranate's peel. Int J Pharm Pharm Sci 2012; 4(3):675-682.

25. Wang Y, You J, Yu Y, Qu C, Zhang H, Ding L. Analysis of ginsenosides in Panax ginseng in high pressure microwave-assisted extraction. Food Chem 2008; 110(1):161-167. doi: http://dx.doi. org/10.1016/j.foodchem.2008.01.028

26. Benmeziane F, Djamai R, Cadot Y, Seridi R. Optimization of extraction parameters of phenolic compounds from Algerian fresh table grapes (Vitis vinifera). Int Food Res J 2014; 21(3):10611065. 